\title{
Effects of tree sapling diversity and nutrient addition on herb-layer invasibility in communities of subtropical species
}

\author{
Sabine Both ${ }^{1^{*}}$, Teng Fang ${ }^{2}$, Martin Baruffol ${ }^{3}$, Bernhard Schmid $^{3}$, Helge Bruelheide ${ }^{1}$, Alexandra \\ Erfmeier $^{1}$ \\ ${ }^{1}$ Institute of Biology/Geobotany and Botanical Garden, Martin Luther University Halle-Wittenberg, Halle (Saale), Germany; \\ *Corresponding Author: sabine.both@botanik.uni-halle.de \\ ${ }^{2}$ Gutianshan National Nature Reserve, Quzhou, China \\ ${ }^{3}$ Institute of Evolutionary Biology and Environmental Studies, University of Zürich, Zürich, Switzerland
}

Received 2 November 2011; revised 5 December 2011; accepted 15 December 2011

\begin{abstract}
Exotic species are assumed to alter ecosystem functioning. However, little is known of the relationships within vertically structured plant communities such as forests, where tree saplings interact with herbaceous species, especially in the early phases of succession. This relationship was tested in a common garden experiment which assessed the impacts on tree saplings and herbaceous species following nutrient addition and the introduction of exotic herb species. The experiment was established in SouthEast China using four broad-leaved tree species (Elaeocarpus decipiens, Schima superba, Castanea henryi and Quercus serrata) to study the relationships between tree sapling diversity, herb-layer productivity and invasibility. Tree saplings were planted in monoculture and in mixtures of two and four species. A full factorial design was applied, within which species composition was crossed with nutrient and exotic seed-addition treatments. The seed-addition treatment included mixtures of seeds from eight exotic herb species, and herb community attributes were assessed after a four month growing season. Results indicate that certain tree species negatively affect native as well as exotic herbs; however, the high productivity of native herbs had a stronger negative impact on exotic species than tree saplings. Nutrient addition increased the productivity of exotic herbs but had no effect on native herbs. Remarkably, exotic species introduction had a negative feedback effect on the growth of tree saplings, which highlights the potential of exotic herbs to diminish tree recruitment. Although tree saplings
\end{abstract}

reduced invasive effects on the herb-layer during the earliest phase of forest succession, nutrient addition had a more profound and opposite effect on these invaders.

Keywords: BEF-China; Early-Successional Communities; Exotic Seed-Addition; Fertilizer Application

\section{INTRODUCTION}

Given recent and predicted rates of global biodiversity loss, ecological research has shifted toward exploring the relationships between biodiversity and ecosystem functioning as a matter of priority [1-4]. Studies from various ecosystem types have revealed the importance of species richness to a range of ecosystem functions and identified that diverse communities are both more productive $[5,6]$ and more stable (e.g. increased invasion resistance $[7,8]$ ). Investigations into current threats to biodiversity have revealed that in addition to habitat loss and exotic species invasion, increased nitrogen deposition negatively affects plant diversity [9-11]. However, regions of high biodiversity [12] are also being increasingly subjected to major anthropogenic disturbance, particularly in developing countries economies, such as increased resource use or industrial emissions including $\mathrm{NO}_{\mathrm{x}}[13,14]$.

Subtropical regions of East and South-East Asia host high levels of vascular plant species richness [12], but countries of the regions, and in particular China with its high level of economic and industrial growth and vast population, still have nature conservation systems that lag behind their increasing environmental problems [15, 16]. Negative impacts of human activities on natural ecosystems have led to an increasing number of naturalized exotic species [17-19], thus increasing the risk of 
native species loss [20-22]. Biodiversity loss caused by habitat degradation and detrimental human disturbance, particularly in managed forests, necessitates a deeper understanding of the relationship between biodiversity and ecosystem functioning in subtropical forests [11,23].

Reforestation and afforestation initiatives in China [24] have emphasized the relevance of maintaining forest biodiversity and protecting it against exotic species invasion [25]. The effects of changing biodiversity on forest invasibility are rarely investigated in experimental communities due to the challenging conditions of setting up a sufficient number of replicate plots (with a few exceptions: see [26]). While insights into biodiversity-invasibility relationships have been gained from grassland experiments $[7,8]$, these may not apply to other systems, e.g. where herbaceous species compete with woody species. The vertical orientation within woodlands may allow for niche complementarity and facilitation, but this structural attribute may also lead to strong asymmetric competition for light between woody species and herbs. In the earliest phase of forest succession, herb species as well as tree saplings occur within the herb-layer simultaneously until tree saplings develop a distinct tree-layer. However, already at this earliest phase, herbaceous and woody species may be more different from each other than species within a purely herbaceous community; due to intrinsic morphological and functional characteristics associated with secondary growth and the woody habit of tree saplings.

Biodiversity effects between structural strata on ecosystem functions are expected in mature forests where tree-layer attributes have been shown to have a significant impact on herb-layer properties $[27,28]$, but it is unclear at what stage of forest succession the impact of tree individuals and tree species diversity on the herblayer becomes manifest, i.e. when the shift from herbdominated to tree-dominated communities occurs. Compagnoni and Halpern [29] observed that during early succession in temperate forests, exotic herb invasion was limited by the developing tree- and shrub-layers, whereas native herbs had no influence on exotic herbs. However, as far as we are aware, no experiments have been carried out that directly test the influence of diverse tree saplings on herb productivity and invasibility during the early stages of forest succession. Furthermore, it is not clear how the environmental context, e.g. nutrient availability, may modify the potential effects $[27,30]$.

Here, we present results from our pioneering experiment on the effects of tree sapling diversity and composition on herb-layer productivity and invasibility during the earliest stages of succession in a subtropical forest ecosystem. We used the platform of a Biodiversity-Ecosystem Functioning project in China (BEF-China [31]) to set up replicated experimental plots with controlled tree species diversity and composition, factorially crossed with fertilizer- and exotic seed-addition treatments. Our measurements were focused on the dynamics of the herblayer community consisting of spontaneously appearing native and introduced exotic herbs. The objectives were to analyze the impacts of tree sapling diversity on 1) the self-assembled native herb-layer and 2) the invasive capacity of exotic herbs. Furthermore, we assessed the role of nutrient addition and native herb-layer attributes as covariates on exotic herb invasion. We expected to discover strong effects of tree sapling diversity and composition on productivity and invasion success of exotic herbs, with weaker effects arising from spontaneously appearing native herbs, and that these effects would be modified by nutrient addition.

\section{MATERIALS AND METHODS}

\subsection{Study Site and Experimental Design}

In the context of the research platform of BEF-China (DFG FOR 891), we established a common garden experiment in the Jiangxi Province of South-East China. The subtropical climate in this region is warm-temperate with warm summers and a short dry season between November and December.

The experimental site was located on a former agricultural field in the floodplain of a river previously used for the cultivation of rice, wheat and other crops (7900 $\mathrm{m}^{2}$; N29 $06.293 \mathrm{E} 117^{\circ}$ 55.286). The site was ploughed and harrowed prior to the establishment of the experiment in March 2009, and 154 experimental plots $\left(1 \mathrm{~m}^{2}\right.$ per plot) were set up within four separate blocks. Shallow drainage ditches $(15-30 \mathrm{~cm})$ surrounded the plots, which were separated by walkways, and deeper channels $(50 \mathrm{~cm})$ bordered each block and led the water to the main run-off ditch to avoid flooding during the rainy season.

Sixteen saplings ( age of 6 month, $30 \mathrm{~cm}$ high) from a pool of four broad-leaved forest species were planted in each plot representing eleven distinct experimental communities consisting of the following: four monocultures, six distinct mixtures of two species $(8+8$ individuals $)$ and one mixture comprising all four species $(4+4+4+$ 4 individuals). The saplings were evenly distributed within the plots with $25 \mathrm{~cm}$ spacing and the plots were randomly assigned to each block. In the first block, individuals within each community were positioned regularly, while in the remaining three blocks, the planting position was randomly assigned, randomizing first the four individuals in the centre in order to guarantee the respective diversity level, and afterwards the twelve individuals at the edge of the experimental plot.

The saplings were raised as seedlings in local nurseries during winter/spring 2008/2009. Seeds were collected 
in the surrounding forests in autumn 2008 and saplings were transplanted from the nurseries to the experimental plots at the end of March 2009 when they had reached an average height of $30 \mathrm{~cm}$. All plots were initially weeded to mitigate sapling mortality and saplings that did not survive the planting procedure were replaced during the first four weeks.

The four tree species used in this experiment were the evergreens Elaeocarpus decipiens Hemsley and Schima superba Gardner \& Champion, and the deciduous Quercus serrata Murray and Castanea henryi (Skan) Rehder \& E. H. Wilson. Using the 11 tree communities allowed us to test for effects of species richness (i.e. three diversity levels 1, 2, 4; diversity effect) as well as effects of presence/absence of single species and their interactions with main factors (species identity effect). In addition to the different experimental communities, we applied fertilizer- and exotic seed-addition treatments in a factorial design to randomly chosen plots. Eight exotic herbaceous species, selected according to their abundance in the Jiangxi and nearby Zhejiang provinces (collected in 2008), were sown into mixtures to test their invasion potential (Table 1). Each exotic species was represented by 150 seeds per mixture applied to each plot. Fertilizer was applied shortly before seed-addition and plots received $13 \mathrm{~g} \cdot \mathrm{N} \cdot \mathrm{m}^{2} \cdot \mathrm{yr}^{-1}$ added as NPK (17-13-15) standard fertilizer.

At the end of May 2009, after weeding of the plots, the seed mixtures were sown into the bare ground at the centre of each plot $(0.6 \times 0.6 \mathrm{~m})$ along with the four tree saplings, representing the respective tree diversity level. The remaining plot area acted as a buffer zone with the same treatment combination (tree diversity $\times$ fertilizer) but without seed-addition. After seed-addition, no further weeding was done, allowing native herb species to colonize the plots. At the end of September 2009, the total number of individuals (abundance) and the number of reproducing individuals of each herb species were counted.

The height of each species was assessed by averaging the height of five randomly selected individuals. These values were used to calculate the abundance-weighted mean height of the herb-layer. In addition, herb-layer aboveground biomass was determined by harvesting each species separately. The harvested plant material was oven-dried $\left(70^{\circ} \mathrm{C} 48 \mathrm{~h}\right)$ and weighed.

Individual tree height was assessed at the beginning and end of the experiment. For all 154 plots, soil samples were taken after biomass harvest from the uppermost 5 $\mathrm{cm}$ of the soil at the centre of each plot. Soil $\mathrm{pH}$ was determined in air-dried subsamples. Total carbon and nitrogen were determined with an elemental analyzer (Elementar Vario ELIII).

\subsection{Data Analyses}

The data were analysed with mixed models (proc
Table 1. Exotic species used in the experimental seed-addition treatment. The classification of invasiveness according to Liu et al. [32] decreases from Group I and Group II to Group III.

\begin{tabular}{|c|c|c|c|}
\hline Species & Family & Life cycle & $\begin{array}{c}\text { Invasiveness } \\
\text { in China }\end{array}$ \\
\hline Ageratum conyzoides L. & Asteraceae & Annual & Group I \\
\hline Amaranthus spinosus L. & Amaranthaceae & Annual & Group I \\
\hline $\begin{array}{l}\text { Chenopodium } \\
\text { ambrosioides L. }\end{array}$ & Chenopodiaceae & Annual & Group II \\
\hline $\begin{array}{l}\text { Crassocephalum } \\
\text { crepidioides (Benth.) S. } \\
\text { Moore }\end{array}$ & Asteraceae & Annual & $*$ \\
\hline Oenothera biennis L. & Onagraceae & $\begin{array}{l}\text { Annual, } \\
\text { biennial }\end{array}$ & $*$ \\
\hline Phytolacca americana L. & Phytolaccaee & Perennial & Group II \\
\hline $\begin{array}{l}\text { Sesbania } \\
\text { cannabina (Retzius) } \\
\text { Poiret }\end{array}$ & Leguminosae & Annual & $* *$ \\
\hline Solidago canadensis L. & Asteraceae & Perennial & Group III \\
\hline
\end{tabular}

*Very frequent in the study area (personal observation), ${ }^{* *}$ frequent in other regions of the province (personal communication with local experts), roughly corresponding to Groups I and II, respectively.

mixed, SAS 9.1, SAS Institute Inc. 2002). In the full model, we used data of all 154 plots and tree diversity level and fertilizer- and seed-addition treatments were considered fixed effects, while block and plot were considered random effects. Diversity was included as a continuous variable and Post-hoc Tukey-Kramer tests were used to compare group means.

Edaphic conditions (soil pH and soil carbon:nitrogen ratio) were analysed as response variables with tree diversity and treatments as explanatory terms. The total biomass of the herb-layer was used as a response variable reflecting productivity, and further response variables analysed included herb species richness, total abundance (summed species abundance), total cover (summed species cover) and mean height of the herblayer $(\mathrm{N}=154)$.

Separate analyses of native herb species were conducted with data from the plots without seed-addition $(\mathrm{N}=66)$, while variables of exotic herbs were separately analysed in the plots with exotic seed-addition $(\mathrm{N}=88)$. To address our third objective, we used species richness and biomass of the native herbs as covariates in the mixed model applied to the set of exotic seed-addition plots $(\mathrm{N}=88)$ only.

In addition, we tested for effects of the presence of each particular tree species (as indicator variables with presence/absence treatment levels) and their interactions 
with tree diversity and fertilizer treatment. In order to account for multiple comparisons when testing each of the four tree species, significance levels were reduced to $\alpha=0.0125$ following Bonferroni adjustment $(\alpha / 4$, i.e. number of multiple comparisons).

\section{RESULTS}

Tree saplings showed remarkable growth during the experiment with the maximum final tree height reaching $114.7 \mathrm{~cm}$. The mean height of the tree saplings was 70.1 $\mathrm{cm}$ and the mean height of the herb-layer across all treatments was $51.8 \mathrm{~cm}$. Native herbaceous species recolonised the plots immediately after weeding and exotic species were not detected in plots without seed-addition, which confirms that exotics were absent in the local seed bank. Total herb-layer species richness at the final monitoring stage ranged from 2 - 15 species. The full model $(\mathrm{N}=154$ plots $)$ revealed that seed-addition caused a significant increase in total herb species richness as well as significantly higher productivity of the herb-layer (Table 2). Native species richness was not affected by exotic seed-addition (data not shown). Productivity of the herb-layer was increased by fertilizer application, but in fertilized conditions, species richness was significantly lower than in unfertilized plots (Table 2).

The overall model revealed no impact of tree sapling diversity on herb-layer attributes, but soil $\mathrm{pH}$ increased with increasing tree species richness. Fertilizer had a significant negative influence on $\mathrm{pH}$. The height increment of the tree saplings was negatively affected by exotic seed-addition (mean increase in absolute height 40.6 cm versus $35.2 \mathrm{~cm}$, Table 2 ).

\subsection{Effects of Tree Diversity on Native Herb-Layer Attributes (Plots without Seed-Addition)}

Tree sapling diversity did not affect the investigated attributes of native herb species. We could not detect differences in abundance, biomass, cover, height or species richness of native herb communities with regard to tree sapling diversity (Figures 1(a)-(e), Table 3).

Table 2. Results from the mixed model analyses for herb-layer, tree saplings and soil characteristics of all experimental plots $(\mathrm{N}=$ 154).

\begin{tabular}{|c|c|c|c|c|c|c|c|c|c|c|c|c|c|c|c|c|c|}
\hline & \multicolumn{4}{|c|}{ Total species richness } & \multicolumn{4}{|c|}{ Total herb biomass } & \multicolumn{2}{|c|}{$\begin{array}{r}\text { Tree height } \\
\text { increment }\end{array}$} & \multicolumn{4}{|c|}{ Soil pH } & \multicolumn{3}{|c|}{ Soil CN ratio } \\
\hline Source of variation & $\mathrm{F}$ & $\mathrm{P}$ & & & $\mathrm{F}$ & $\mathrm{P}$ & & & $\mathrm{F}$ & $\mathrm{P}$ & & $\mathrm{F}$ & $\mathrm{P}$ & & & $\mathrm{F}$ & $\mathrm{P}$ \\
\hline Tree diversity & 2.28 & 0.133 & & & 0.15 & 0.702 & & & 0.05 & 0.819 & & 8.24 & 0.005 & ** & $\uparrow$ & 0.61 & 0.437 \\
\hline Fertilizer & 30.98 & $<0.001$ & $* * *$ & $\downarrow$ & 16.72 & $<0.001$ & $* * *$ & $\uparrow$ & 0.9 & 0.345 & & 155.87 & $<0.001$ & *** & $\downarrow$ & 0.48 & 0.489 \\
\hline Tree diversity ${ }^{*}$ Fertilizer & 0.11 & 0.740 & & & 0 & 0.996 & & & 0.3 & 0.582 & & 0.02 & 0.899 & & & 0.18 & 0.671 \\
\hline Seed addition & 170.39 & $<0.001$ & $* * *$ & $\uparrow$ & 122.79 & $<0.001$ & $* * *$ & $\uparrow$ & 4.37 & 0.038 & $* \quad \downarrow$ & 1.38 & 0.242 & & & 1.77 & 0.186 \\
\hline $\begin{array}{l}\text { Tree diversity }{ }^{*} \text { Seed } \\
\text { addition }\end{array}$ & 0.84 & 0.360 & & & 1.3 & 0.256 & & & 1.56 & 0.214 & & 0.15 & 0.703 & & & 0.77 & 0.381 \\
\hline Fertilizer ${ }^{*}$ Seed addition & 2.79 & 0.097 & & & 9.99 & 0.002 & & & 0.73 & 0.393 & & 0.45 & 0.503 & & & 1.48 & 0.226 \\
\hline $\begin{array}{l}\text { Tree diversity }{ }^{*} \text { Fertilizer } \\
{ }^{*} \text { Seed addition }\end{array}$ & 0.09 & 0.759 & & & 1.7 & 0.195 & & & 0.11 & 0.743 & & 3.58 & 0.061 & & & 0.38 & 0.537 \\
\hline
\end{tabular}

In all cases, the numerator DF was 1 and denominator DFs were 143, 140, 142, 142 and 129 for total species richness, total herb biomass, tree height increment, soil $\mathrm{pH}$ and soil $\mathrm{CN}$ ratio, respectively. Block is considered a random effect and a $\mathrm{Z}$ value instead of an $\mathrm{F}$ value is provided. Arrows indicate significant increase $(\uparrow)$ or decrease $(\downarrow)$ of the response variables with increasing levels of main factors. Significance levels are “"***" $<0.001$; “**” $<0.01$; “"” $<0.05$. 
(a)

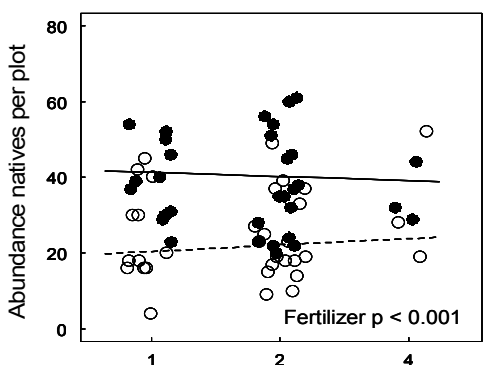

(b)

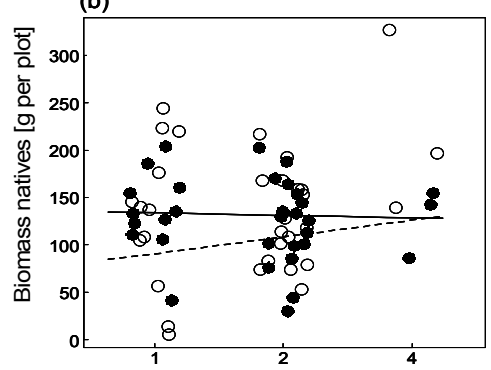

(c)

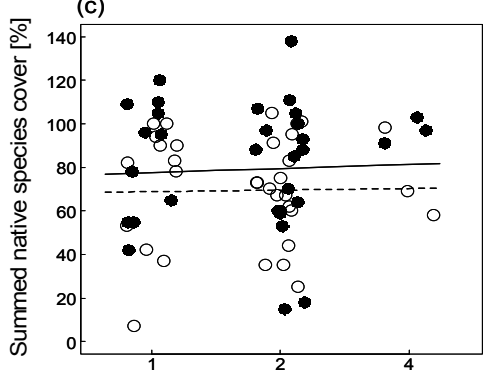

(d)

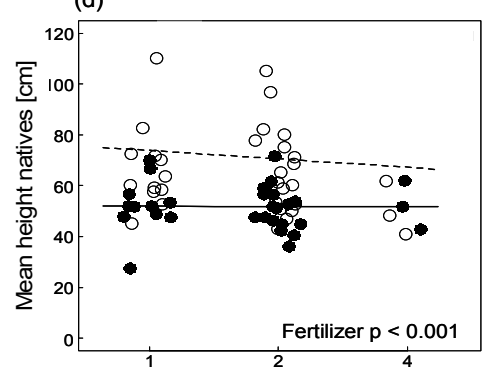
(e)

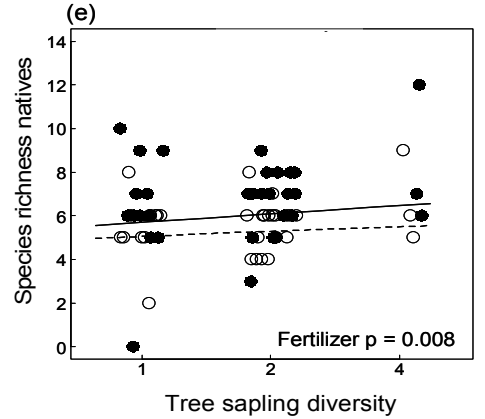

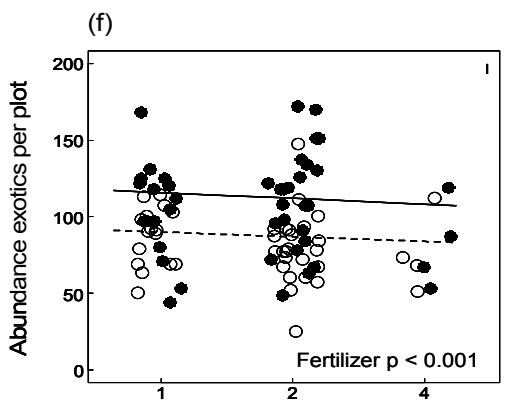

(g)

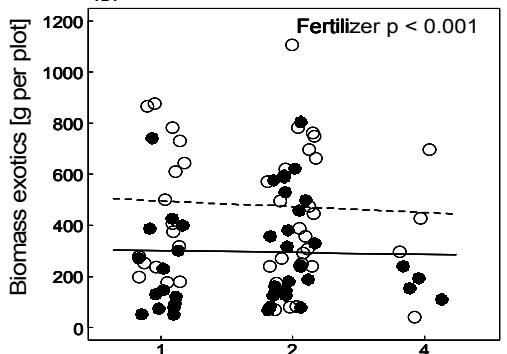

(h)
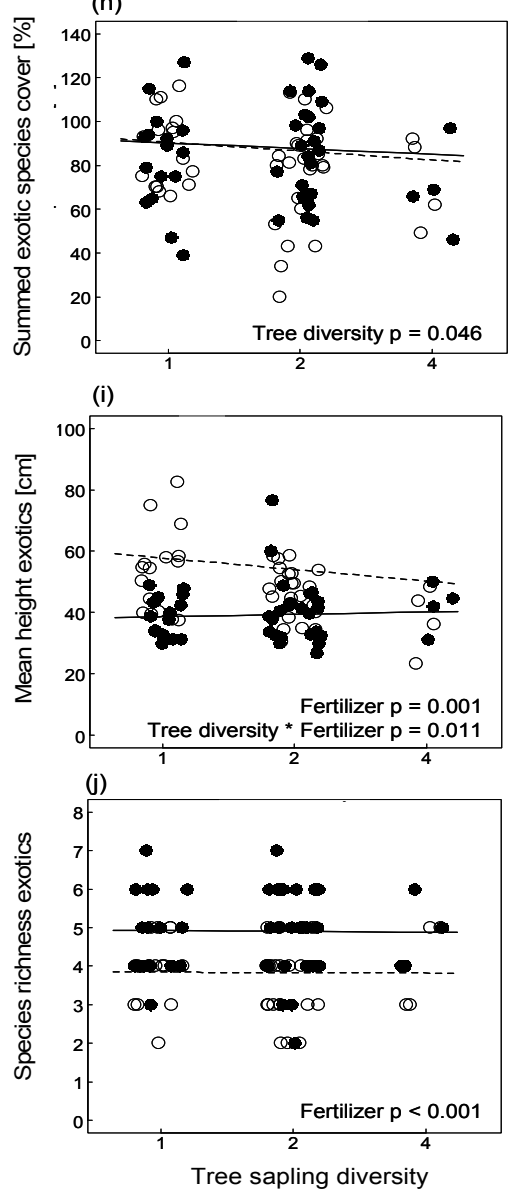

Figure 1. Attributes of the herb-layer as a function of tree sapling diversity; points are jittered for clarity. Open circles and dotted lines refer to plots which received fertilizer, filled circles and solid lines show non-fertilized plots. Variables of native species (a-e) correspond to plots without seed-addition $(\mathrm{N}=66$ ); exotic species variables ( $\mathrm{f}-\mathrm{j})$ were calculated from plots with seed- addition $(\mathrm{N}=88)$. Tree sapling diversity is shown on a log-scale. Regression lines are based on the mixed models performed separately for native and exotic species (see Tables 3 and 4, respectively). Significant factors are mentioned in the graphs. 


\subsection{Effects of Tree Diversity on Exotic Species Invasion (Seed-Addition Plots)}

With the exception of Solidago canadensis, all introduced exotic species germinated and total abundance exceeded that of native herbaceous species by more than a factor of two (Figure 1(f)). Furthermore, apart from Oenothera biennis, all of the seven exotic species that germinated developed flowers and seeds. Crassocephalum crepidioides, Ageratum conyzoides (both Asteraceae) and Sesbania cannabina (Fabaceae) occurred most frequently. Sesbania cannabina showed the highest maximum abundance, at 81 individuals per $0.6 \times 0.6 \mathrm{~m}$ subplot in the seed-addition treatment, and it grew tallest, even exceeding the height of the tree individuals (data not shown). Within the experimental communities, seedaddition led to the successful establishment of 2 - 7 exotic species per plot. The cover of exotic species was significantly affected by tree sapling diversity, with reduced species cover occurring under a more diverse tree-layer.

\subsection{Effects of Fertilizer Treatment on Herb-Layer Attributes}

Fertilizer application significantly decreased native herb species richness and abundance but had no effect on native species productivity (Figures 1(a), (d)-(e), Table 3). In contrast, total biomass of exotic species (in plots with seed-addition) was more than four times as high as total biomass of native species in plots without seedaddition and was further increased by a factor of 1.5 by fertilizer application (Figure 1(g), Table 4). At the same time, fertilizer application caused a significant decrease in exotic species abundance (Figure 1(f)) and richness (Figure 1(j)) but increased mean height of exotic species (Table 4). In addition, the mean height of exotics was reduced by tree sapling diversity under high fertilizer conditions only (significant two-way interaction between tree diversity and fertilizer addition treatment; see Table 4 and Figure 1(i)), thus resulting in a non-significant overall effect of tree sapling diversity.

Table 3. Results of the mixed model of plots without seed-addition $(\mathrm{N}=66)$ for variables of native species.

\begin{tabular}{|c|c|c|c|c|c|c|c|c|c|c|c|c|c|c|c|}
\hline Native species & & & & & & & & & & & & & & & \\
\hline & Abun & dance & & & & nass & & & Mean & height & & & & iness & \\
\hline Source of variation & $\mathrm{F}$ & $P$ & & & $\mathrm{~F}$ & $\mathrm{P}$ & $\mathrm{F}$ & $\mathrm{P}$ & $\mathrm{F}$ & $\mathrm{P}$ & & & $\mathrm{F}$ & $P$ & \\
\hline Block & 0.95 & 0.171 & & & 0.13 & 0.450 & 0.68 & 0.248 & 0.19 & 0.423 & & & 0.73 & 0.231 & \\
\hline Tree diversity & 0.13 & 0.723 & & & 1.71 & 0.196 & 0.25 & 0.616 & 1.67 & 0.202 & & & 3.44 & 0.069 & \\
\hline Fertilizer & 23.82 & $<0.001$ & $* * *$ & $\downarrow$ & 0.51 & 0.478 & 3.18 & 0.080 & 15.83 & $<0.001$ & ${ }^{* * *}$ & $\uparrow$ & 7.45 & 0.008 & ${ }^{* *} \quad \downarrow$ \\
\hline $\begin{array}{l}\text { Tree diversity } \\
\text { Fertilizer }\end{array}$ & 1.36 & 0.248 & & & 3 & 0.089 & 0.04 & 0.842 & 1.36 & 0.249 & & & 0.26 & 0.611 & \\
\hline
\end{tabular}

In all cases, the numerator DF was 1 and the denominator DFs were 58,57, 58, 58 and 59 for native species abundance, biomass, cover, mean height and richness, respectively. Block is considered a random effect and a $\mathrm{Z}$ value instead of an $\mathrm{F}$ value is provided. Arrows indicate significant increases $(\uparrow)$ or decreases $(\downarrow)$ of the response variables with increasing tree sapling diversity and with fertilizer application. Significance levels are “***” $<0.001 ;$ “**” $<0.01 ;$ "“"” $<0.05$.

Table 4. Mixed model performed with plots with seed-addition $(\mathrm{N}=88)$ for variables of exotic species.

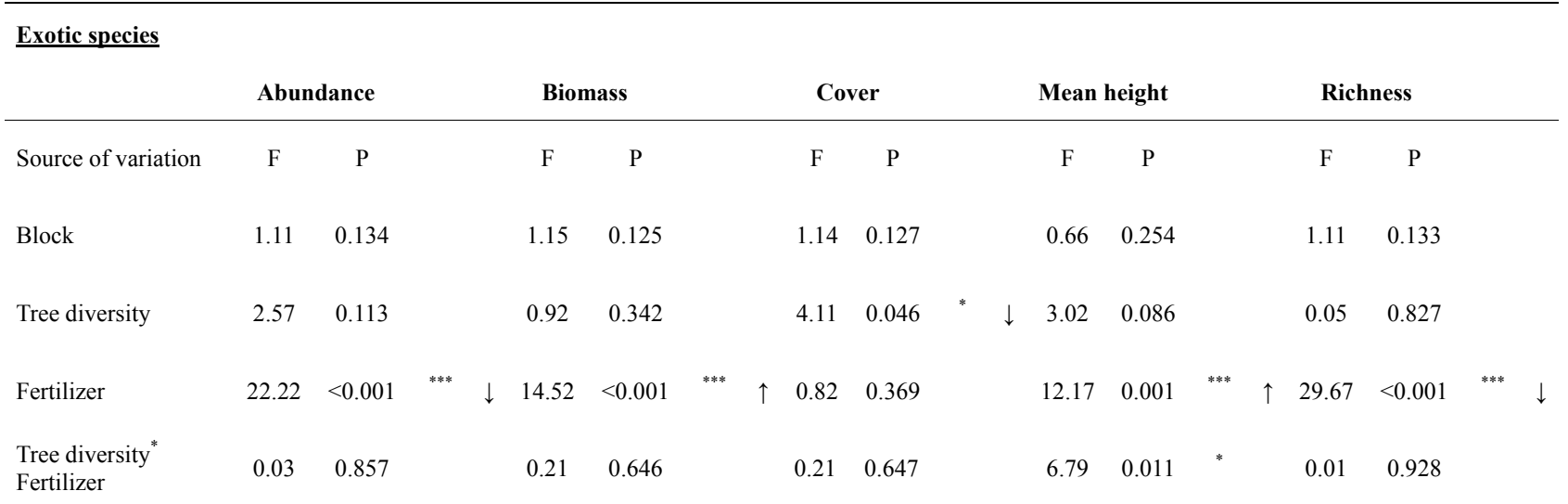

In all cases, the numerator DF was 1 and the denominator DF was 81 except for exotic biomass, where the denominator DF was 80 . Block is considered a random effect and a $\mathrm{Z}$ value instead of an F value is provided. Arrows indicate a significant increase $(\uparrow)$ or decrease $(\downarrow)$ of the response variables with increasing tree sapling diversity and with fertilizer application. Significance levels are " $" * * *,<0.001 ;$ " “*” $<0.01 ;$ “"” $<0.05$. 


\subsection{Effects of Native Herbs on the Invasion of Exotic Species (Seed-Addition Plots)}

Native herb species richness did not affect the variables of exotic species investigated (data not shown). However, biomass, abundance and cover of exotic species were significantly reduced with increasing biomass of the native herbs, while the number of exotic species was not affected (Table 5).

\subsection{Tree Sapling Identity Effects on Herb-Later Attributes}

Analyses of presence/absence of single tree species and their interactions with treatment factors revealed that tree sapling identity caused effects on herbaceous species, independent of tree diversity level. The presence of the evergreen tree species Elaeocarpus decipiens had a significantly negative impact on several herb-layer variables of both native and exotic herbs. It resulted in significantly decreased abundance, productivity and cover of native herbs, and in the seed-addition plots, it depressed the number and abundance of exotic herbs. Of all other tree species in the experiment, only Castanea henryi had a measurable impact on the herb-layer: when present, native herb species cover was significantly increased (supplementary material).

\section{DISCUSSION}

Recent reviews highlight the challenge of integrating more complex model systems in ecosystem research $[4,33]$. While this concept has even been applied to multitrophic levels [34-36], the present study made use of plant communities with a complex structure reflected in varying life forms, i.e. woody vs herbaceous, and a developing height structure. In particular, we wanted to know whether tree sapling diversity had a measurable impact on productivity and invasibility of the herb-layer in the earliest stages of experimental forest succession. Within our early-successional communities of tree saplings and herb species, we found evidence for mutual effects in the very first growing season.

\subsection{Impacts of Tree Saplings}

In general, we observed few significant effects of tree species richness on variables measured for herbs. In contrast to our first objective, the spontaneously occurring native herb species were not influenced by tree sapling richness. This lack of tree diversity control on native herb-layer attributes is in accordance with findings from observational studies in a chronosequence of nearby secondary broad-leaved forest [37]; however, these results were gained from mature forest communities.

While tree sapling richness did not matter for native herb-layer attributes in the early-successional systems investigated, tree sapling identity did. We showed that the presence of one particular tree species, the evergreen Elaeocarpus decipiens, suppressed herbaceous species. This might have been caused by strong light competition from this tree species [26], from litter quality or accumulation [38,39] or from allelopathic effects [40,41]. Remarkably, given the importance of Elaeocarpus decipiens in our experimental communities, we demonstrated that there was a measurable impact from tree sapling type on herb-layer species, and at the very beginning of successional development.

Table 5. Mixed model performed with the seed-addition plots $(\mathrm{N}=88)$ for variables of exotic species with the fixed effects and with biomass of native herb species as covariate are shown.

$\underline{\text { Exotic species }}$

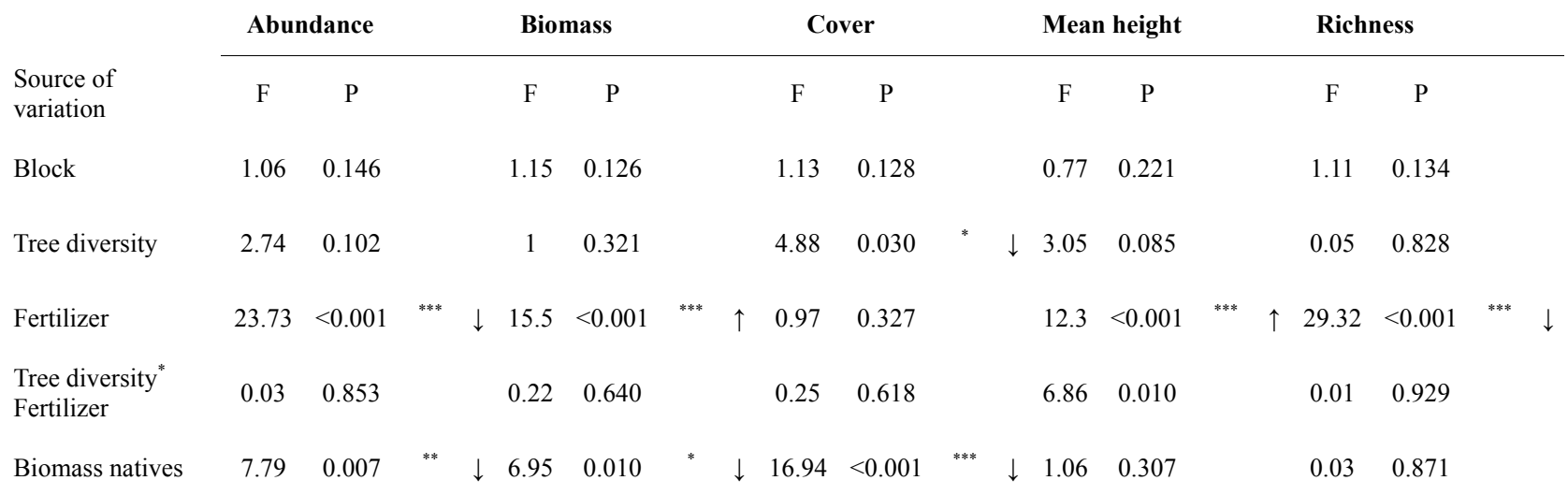

In all cases, numerator DF were 1 and denominator DF were 80 except for exotic biomass, where denominator DF was 79 . Block is considered a random effect and a $\mathrm{Z}$ value instead of $\mathrm{F}$ value is provided. Arrows indicate significant increase $(\uparrow)$ or decrease $(\downarrow)$ of the response variables with increasing tree sapling diversity, with fertilizer application or with increasing biomass of native herb species. Significance levels are “***, $<0.001 ;$ “**”, $<0.01 ;$ “*” $<0.05$. 
Despite a lack of significant effects of tree species richness on native herb-layer attributes, we found some moderate evidence for negative impacts of tree saplings on exotic herb species in these young communities. Tree sapling richness had a negative impact on exotic species cover and, particularly in nutrient-enriched environments, height. This confirms that tree diversity can exert a controlling function on invasibility, already before clearly differentiated structural strata are developed, therefore providing evidence for our second objective, i.e. to the study the effects of tree sapling diversity on the invasive capacity of exotic herbs. This finding complements investigations in grasslands with somewhat dissimilar functional plant groups that detected a negative diversity-invasibility relationship within one structural stratum $[5,42]$. In addition to tree sapling diversity effects, we detected that specific species conferred invasion resistance, as has also been described from grassland studies $[8,43,44]$. The detrimental effects of Elaeocarpus decipiens on exotic species abundance and richness (common measures of invasibility) further demonstrates that attributes of the developing tree-layer, i.e. the vertical structure, affect invasion resistance of the herb-layer in early-successional forest ecosystems. A deeper analysis of the mechanisms that lead to the unfavourable conditions mediated by Elaeocarpus decipiens would be necessary to unravel why native herb species richness, in contrast to exotics, was unaffected by this tree species. Different reactions might arise from co-evolved interactions between native species [45], propagule pressure [46] and directions of feedbacks within the communities [47].

The influence of the other three tree species included in this study on the herb-layer was minor, which demonstrates that effects cannot be exclusively attributed to the evergreen leaf habit, since the presence of the evergreen Schima superba did not reveal any species effects. Considering that the tree species used in the present study only represent a small fraction of the extraordinarily species-rich subtropical forests in the study area [31], it is conceivable that, by chance, our species pool sampled only one tree species that has a strong influence. The expansion of such an experiment to a pool of 42 tree species, as realised in the main experiment of BEF-China [Yang et al., unpublished], will be a good opportunity to overcome this shortcoming and will further disentangle tree species richness from species identity effects on the herb-layer.

\subsection{Covariate Influence on Exotic Species Invasion}

With regard to our third objective, we found strongest negative co-varying impact on diversity of both native and exotic herb species induced by the nutrient enrichment treatment. Nutrient enrichment has already been demonstrated before as driver for biodiversity loss in forests $[11,48]$ and for changes in frequency of forest species [49], remarkably, we detected negative species responses already after a few months. With respect to exotic species, there was only a moderate direct invasion control of tree sapling diversity, but a much stronger interaction effect with fertilizer application. Increasing nutrient deposition in the context of global change $[10,14]$ might lead to stronger diversity effects among forest strata and hence put forward the challenge of incorporating structural and environmental complexity in forest invasion research [50]. The outcome of the present study clearly demonstrates that neglecting the environmental context, in our case altered by fertilizer addition, may obscure biodiversity-ecosystem functioning relationship variations [51].

We also detected a negative impact of native productivity on exotic species productivity, abundance and cover, which is in contrast to the outcome of the observational study by Compagnoni and Halpern [29]. However, in our study, productivity of introduced exotics exceeded productivity of spontaneously germinating natives by several orders of magnitude, and native herbs did not appear to be generally at a disadvantage. The diversity of native herb species did not decrease when exotics became established, which points to functional differences among herbaceous species, resulting in facilitation and complementarity.

In particular, with regard to forest ecosystems, long timescales are necessary to adequately reflect succession and invasion dynamics and to account for temporal community variability $[29,52]$. While our experiment focused on the initial stage of tree recruitment, further investigations are needed to detect whether tree diversity effects on herb-layer attributes become more evident at later successional stages. Identity effects, such as those discovered for Elaeocarpus decipiens, indicate strong components for the developing tree-layer, and follow-up studies will have to test for transferability of these findings on invasibility relationships to real forest ecosystems, with much higher tree species richness and higher structural complexity.

Finally, this study demonstrated that increased nutrient input mediated significant shifts in herb species richness and ecosystem functions without time lag. In general, fertilizer-application and seed-addition treatments had much stronger effects on the herb-layer and led to notable differences between plant communities. These findings emphasize the need for action in regions of accelerating industrialization and agricultural production, particularly where $\mathrm{NO}_{\mathrm{x}}$ emissions affect natural forests.

\section{ACKNOWLEDGEMENTS}

We thank Bing-Yang Ding from Wenzhou University and Mo Gao 
from Hangzhou Normal University for assistance with seed collection and Ricarda Pohl and Christoph Rosche for helping in data collection. Authors thank Daniel McCluskey for linguistic polishing. Financial support was provided by the German Science Foundation (DFG FOR 891/1, ER 573/1-1).

\section{REFERENCES}

[1] Tilman, D. (2000) Causes, consequences and ethics of biodiversity. Nature, $\mathbf{4 0 5}, \mathbf{2 0 8 - 2 1 1 . ~}$

doi: $10.1038 / 35012217$

[2] Loreau, M., Naeem, S., Inchausti, P., Bengtsson, J., Grime, J.P., Hector, A., Hooper, D.U., Huston, M.A., Raffaelli, D., Schmid, B., Tilman, D. and Wardle, D.A. (2001) Biodiversity and ecosystem functioning: Current knowledge and future challenges. Science, 294, 804-808. doi:10.1126/science. 1064088

[3] Balvanera, P., Pfisterer, A.B., Buchmann, N., He, J.S., Nakashizuka, T., Raffaelli, D. and Schmid, B. (2006) Quantifying the evidence for biodiversity effects on ecosystem functioning and services. Ecology Letters, 9, 11461156. doi:10.1111/j.1461-0248.2006.00963.x

[4] Hillebrand, H. and Matthiessen, B. (2009) Biodiversity in a complex world: Consolidation and progress in functional biodiversity research. Ecology Letters, 12, 14051419. doi:10.1111/j.1461-0248.2009.01388.x

[5] Tilman, D. (1997) Community invasibility, recruitment limitation, and grassland biodiversity. Ecology, 78, 81-92. doi:10.1890/0012-9658(1997)078[0081:CIRLAG]2.0.CO ;2

[6] Hector, A., Schmid, B., Beierkuhnlein, C., Caldeira, M.C., Diemer, M., Dimitrakopoulos, P.G., Finn, J.A., Freitas, H., Giller, P.S., Good, J., Harris, R., Hogberg, P., Huss-Danell, K., Joshi, J., Jumpponen, A., Korner, C., Leadley, P.W., Loreau, M., Minns, A., Mulder, C.P.H., O’Donovan, G., Otway, S.J., Pereira, J.S., Prinz, A., Read, D.J., SchererLorenzen, M., Schulze, E.D., Siamantziouras, A.S.D., Spehn, E.M., Terry, A.C., Troumbis, A.Y., Woodward, F.I., Yachi, S. and Lawton, J.H. (1999) Plant diversity and productivity experiments in European grasslands. Science, 286, 1123-1127. doi:10.1126/science. 286.5442 .1123

[7] Hector, A., Dobson, K., Minns, A., Bazeley-White, E. and Lawton, J.H. (2001) Community diversity and invasion resistance: An experimental test in a grassland ecosystem and a review of comparable studies. Ecological Research, 16, 819-831. doi:10.1046/j.1440-1703.2001.00443.x

[8] Roscher, C., Schmid, B. and Schulze, E.D. (2009) Nonrandom recruitment of invader species in experimental grasslands. Oikos, 118, 1524-1540. doi:10.1111/j.1600-0706.2009.17601.x

[9] Lu, X., Mo, J. and Dong, S. (2008) Effects of nitrogen deposition on forest biodiversity. Acta Ecologica Sinica, 28, 5532-5548. doi:10.1016/S1872-2032(09)60012-3

[10] Bobbink, R., Hicks, K., Galloway, J., Spranger, T., Alkemade, R., Ashmore, M., Bustamante, M., Cinderby, S., Davidson, E., Dentener, F., Emmett, B., Erisman, J.W., Fenn, M., Gilliam, F., Nordin, A., Pardo, L. and De Vries, W. (2010) Global assessment of nitrogen deposition ef- fects on terrestrial plant diversity: A synthesis. Journal of Applied Ecology, 20, 30-59. doi:10.1890/08-1140.1

[11] Lu, X.K., Mo, J.M., Gilliam, F.S., Zhou, G.Y. and Fang, Y.T. (2010) Effects of experimental nitrogen additions on plant diversity in an old-growth tropical forest. Global Change Biology, 16, 2688-2700. doi:10.1111/j.1365-2486.2010.02174.x

[12] Barthlott, W., Mutke, J., Rafiqpoor, M.D., Kier, G. and Kreft, H. (2005) Global centres of vascular plant diversity. Nova Acta Leopoldina, 92, 61-83.

[13] Zheng, X., Fu, C., Xu, X., Yan, X., Huang, Y., Han, S., $\mathrm{Hu}, \mathrm{F}$. and Chen, G. (2002) The Asian nitrogen cycle case study. Ambio, 31, 79-87. doi:10.1579/0044-7447-31.2.79

[14] Galloway, J.N., Dentener, F.J., Capone, D.G., Boyer, E.W., Howarth, R.W., Seitzinger, S.P., Asner, G.P., Cleveland, C.C., Green, P.A., Holland, E.A., Karl, D.M., Michaels, A.F., Porter, J.H., Townsend. A.R. and Vorosmarty, C.J. (2004) Nitrogen cycles: Past, present, and future. Biogeochemistry, 70, 153-226. doi:10.1007/s10533-004-0370-0

[15] Lopez-Pujol, J., Zhang, F.M. and Ge, S. (2006) Plant biodiversity in China: Richly varied, endangered, and in need of conservation. Biodiversity and Conservation, 15, 3983-4026. doi:10.1007/s10531-005-3015-2

[16] Fu, Y, Chen, J, Guo, H., Hu, H., Chen, A. and Cui, J. (2010) Agrobiodiversity loss and livelihood vulnerability as a consequence of converting from subsistence farming systems to commercial plantation-dominated systems in Xishuangbanna, Yunnan, China: A household level Analysis. Land Degradation \& Development, 21, 274-284.

[17] Liu, J., Liang, S.C., Liu, F.H., Wang, R.Q. and Dong, M. (2005) Invasive alien plant species in China: Regional distribution patterns. Diversity and Distributions, 11, 341347. doi:10.1111/j.1366-9516.2005.00162.x

[18] Weber, E., Sun, S.G. and Li, B. (2008) Invasive alien plants in China: Diversity and ecological insights. Biological Invasions, 10, 1411-1429. doi:10.1007/s10530-008-9216-3

[19] Feng, J. and Zhu, Y. (2010) Alien invasive plants in China: Risk assessment and spatial patterns. Biodiversity and Conservation, 19, 3489-3497. doi:10.1007/s10531-010-9909-7

[20] Mack, R.N., Simberloff, D., Lonsdale, W.M., Evans, H., Clout, M. and Bazzaz, F.A. (2000) Biotic invasions: Causes, epidemiology, global consequences, and control. Journal of Applied Ecology, 10, 689-710. doi:10.1890/1051-0761(2000)010[0689:BICEGC]2.0.CO ;2

[21] Meiners, S.J., Pickett, S.T.A. and Cadenasso, M.L. (2001) Effects of plant invasions on the species richness of abandoned agricultural land. Ecography, 24, 633-644. doi:10.1111/j.1600-0587.2001.tb00525.x

[22] Hejda, M., Pysek, P. and Jarosik, V. (2009) Impact of invasive plants on the species richness, diversity and composition of invaded communities. Journal of Ecology, 97, 393-403. doi:10.1111/j.1365-2745.2009.01480.x

[23] Wang, X.H., Kent, M. and Fang, X.F. (2007) Evergreen broad-leaved forest in Eastern China: Its ecology and con- 
servation and the importance of resprouting in forest restoration. Forest Ecology and Management, 245, 76-87. doi:10.1016/i.foreco.2007.03.043

[24] Song, C. and Zhang, Y. (2010) Forest cover in China from 1949 to 2006, In: Nagendra, H. and Southworth, J., Eds., Reforesting Landscapes: Linking Pattern and Process, Landscape Series 10, Springer, Dordrecht, 341-356.

[25] Brockerhoff, E.G., Jactel, H., Parrotta, J.A., Quine, C.P. and Sayer, J. (2008) Plantation forests and biodiversity: Oxymoron or opportunity? Biodiversity and Conservation, 17, 925-951. doi:10.1007/s10531-008-9380-x

[26] Knight, K.S., Oleksyn, J., Jagodzinski, A.M., Reich, P.B. and Kasprowicz, M. (2008) Overstorey tree species regulate colonization by native and exotic plants: A source of positive relationships between understorey diversity and invasibility. Diversity and Distributions, 14, 666-675. doi:10.1111/j.1472-4642.2008.00468.x

[27] Gilliam, F.S. (2007) The ecological significance of the herbaceous layer in temperate forest ecosystems. BioScience, 57, 845-858. doi:10.1641/B571007

[28] Mölder, A., Bernhardt-Römermann, M. and Schmidt, W. (2008) Herb-layer diversity in deciduous forests: Raised by tree richness or beaten by beech? Forest Ecology and Management, 256, 272-281. doi:10.1016/j.foreco.2008.04.012

[29] Compagnoni, A. and Halpern, C.B. (2009) Properties of native plant communities do not determine exotic success during early forest succession. Ecography, 32, 449-458. doi:10.1111/j.1600-0587.2008.05739.x

[30] Chandy, S. and Gibson, D.J. (2009) Scale dependency of species composition and environmental variables in the strata of a deciduous forest. Community Ecology, 10, 121130. doi:10.1556/ComEc.10.2009.1.14

[31] Bruelheide, H., Böhnke, M., Both, S., Fang, T., Assmann, T., Baruffol, M., Bauhus, J., Buscot, F., Chen, X.Y., Ding, B.Y., Durka, W., Erfmeier, A., Fischer, M., Geißler, C., Guo, D., Guo, L.D., Härdtle, W., He, J.S., Hector, A., Kröber, W., Kühn, P., Lang, A.C., Nadrowski, K., Pei, K., Scherer-Lorenzen, M., Shi, X., Scholten, T., Schuldt, A., Trogisch, S., von Oheimb, G., Welk, E., Wirth, C., Wu, Y.T., Yang, X., Zeng, X., Zhang, S., Zhou, H., Ma, K. and Schmid, B. (2011) Community assembly during secondary forest succession in a Chinese subtropical forest. Ecological Monographs, 81, 25-41. doi:10.1890/09-2172.1

[32] Liu, J., Dong, M., Miao, S.L., Li, Z.Y., Song, M.H. and Wang, R.Q. (2006) Invasive alien plants in China: Role of clonality and geographical origin. Biological Invasions, $\mathbf{8}$, 1461-1470. doi:10.1007/s10530-005-5838-X

[33] Duffy, J.E., Cardinale, B.J., France, K.E., McIntyre, P.B., Thebault, E. and Loreau, M. (2007) The functional role of biodiversity in ecosystems: Incorporating trophic complexity. Ecology Letters, 10, 522-538. doi:10.1111/j.1461-0248.2007.01037.x

[34] Reiss, J., Bridle, J.R., Montoya, J.M. and Woodward, G. (2009) Emerging horizons in biodiversity and ecosystem functioning research. Trends in Ecology \& Evolution, 24, 505-514. doi:10.1016/j.tree.2009.03.018

[35] Srivastava, D.S., Cardinale, B.J., Downing, A.L., Duffy,
J.E., Jouseau, C., Sankaran, M. and Wright, J.P. (2009) Diversity has stronger top-down than bottom-up effects on decomposition. Ecology, 90, 1073-1083. doi:10.1890/08-0439.1

[36] Scherber, C., Eisenhauer, N., Weisser, W.W., Schmid, B., Voigt, W., Fischer, M., Schulze, E.D., Roscher, C., Weigelt, A., Allan, E., Bessler, H., Bonkowski, M., Buchmann, N., Buscot, F., Clement, L.W., Ebeling, A., Engels, C., Halle, S., Kertscher, I., Klein, A.M., Koller, R., Konig, S., Kowalski, E., Kummer, V., Kuu, A., Lange, M., Lauterbach, D., Middelhoff, C., Migunova, V.D., Milcu, A., Muller, R., Partsch, S., Petermann, J.S., Renker, C., Rottstock, T., Sabais, A., Scheu, S., Schumacher, J., Temperton, V.M. and Tscharntke, T. (2010) Bottom-up effects of plant diversity on multitrophic interactions in a biodiversity experiment. Nature, 468, 553-556. doi:10.1038/nature09492

[37] Both, S., Fang, T., Böhnke, M., Bruelheide, H., Geißler, C., Kühn, P., Scholten, T., Trogisch, S. and Erfmeier, A. (2011) Lack of tree layer control on herb layer characteristics in a subtropical forest, China. Journal of Vegetation Science, 22, 1120-1131. doi:10.1111/j.1654-1103.2011.01324.x/abstract

[38] Schimpf, D.J. and Danz, N.P. (1999) Light passage through leaf litter: Variation among northern hardwood trees. Agricultural and Forest Meteorology, 97, 103-111. doi:10.1016/S0168-1923(99)00064-7

[39] Sariyildiz, T., Anderson, J.M. and Kucuk, M. (2005) Effects of tree species and topography on soil chemistry, litter quality, and decomposition in Northeast Turkey. Soil Biology \& Biochemistry, 37, 1695-1706. doi:10.1016/j.soilbio.2005.02.004

[40] Gilliam, F.S. and Roberts M.R. (2003) Interactions between the herbaceous layer and overstory canopy of Eastern forests. In: Gilliam, F.S., Roberts, M.R., Eds., The Herbaceous Layer in Forests of Eastern North America. Oxford University Press, Oxford, 198-223.

[41] Härdtle, W., von Oheimb, G. and Westphal, C. (2003) The effects of light and soil conditions on the species richness of the ground vegetation of deciduous forests in northern Germany (Schleswig-Holstein). Forest Ecology and Management, 182, 327-338. doi:10.1016/S0378-1127(03)00091-4

[42] Naeem, S., Knops, J.M.H., Tilman, D., Howe, K.M., Kennedy, T. and Gale, S. (2000) Plant diversity increases resistance to invasion in the absence of covarying extrinsic factors. Oikos, 91, 97-108. doi:10.1034/j.1600-0706.2000.910108.x

[43] van Ruijven, J., De Deyn, G.B. and Berendse, F. (2003) Diversity reduces invasibility in experimental plant communities: The role of plant species. Ecology Letters, 6, 910-918. doi:10.1046/j.1461-0248.2003.00516.x

[44] Emery, S.M. and Gross, K.L. (2006) Dominant species identity regulates invasibility of old-field plant communities. Oikos, 115, 549-558. doi:10.1111/j.2006.0030-1299.15172.x

[45] Jiang, X.L., Zhang, W.G. and Wang, G. (2007) Biodiversity effects on biomass production and invasion resistance in annual versus perennial plant communities. Biodiver- 
sity and Conservation, 16, 1983-1994. doi:10.1007/s10531-006-9061-6

[46] Thomsen, M.A., D'Antonio, C.M., Suttle, K.B. and Sousa, W.P. (2006) Ecological resistance, seed density and their interactions determine patterns of invasion in a California coastal grassland. Ecology Letters, 9, 160-170. doi:10.1111/j.1461-0248.2005.00857.x

[47] Eppstein, M.J. and Molofsky, J. (2007) Invasiveness in plant communities with feedbacks. Ecology Letters, 10, 253-263. doi:10.1111/j.1461-0248.2007.01017.x

[48] Gilliam, F.S. (2006) Response of the herbaceous layer of forest ecosystems to excess nitrogen deposition. Journal of Ecology, 94, 1176-1191. doi:10.1111/j.1365-2745.2006.01155.x

[49] Jandt, U., von Wehrden, H. and Bruelheide, H. (2011) Exploring large vegetation databases to detect temporal trends in species occurrences. Journal of Vegetation Science, 22, 957-972. doi:10.1111/j.1654-1103.2011.01318.x

[50] Luken, J.O. (2003) Invasions of forests in the eastern United States. In: Gilliam, F.S., Roberts, M.R. Eds., The Herbaceous Layer in Forests of Eastern North America. Oxford University Press, Oxford, 283-301.

[51] Fridley, J.D. (2002) Resource availability dominates and alters the relationship between species diversity and ecosystem productivity in experimental plant communities. Oecologia, 132, 271-277. doi:10.1007/s00442-002-0965-x

[52] Meiners, S.J., Pickett, S.T.A. and Cadenasso, M.L. (2002) Exotic plant invasions over 40 years of old field successions: Community patterns and associations. Ecography, 25, 215-223. doi:10.1034/j.1600-0587.2002.250209.x 